Received Date : 26-Jun-2015

Revised Date : 23-Sep-2015

Accepted Date : 29-Oct-2015

Article type : Case Report (online only)

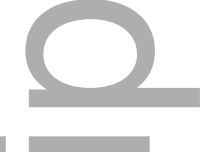

Title: Diabetic Medicine

Created by: Maria Hale

Email proofs to: paul.wraight@mh.org.au

Copyright: Diabetes UK

Article no.: DME-2015-00502

Article type: Case Report

Figures:1; Tables:0; Equations:0; References: 5

Short title/Authors running head: Rare mimic of pedal osteomyelitis in a patient with Type 2 diabetes $\bullet S$.

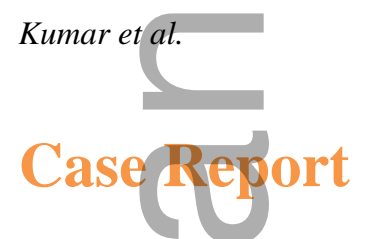

\title{
Rare mimic of pedal osteomyelitis in a patient with
}

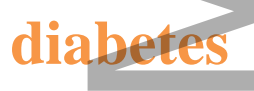

\section{S. Kumar, M. Kyi and P. R. Wraight}

Department of Diabetes and Endocrinology, The Royal Melbourne Hospital, Parkville, VIC, Australia

Correspondence to: Paul Wraight. E-mail: Paul.Wraight@mh.org.au

\section{What's new?}

- Atypical presentations of suspected diabetic foot osteomyelitis should raise suspicion of potential rare mimics and be further investigated with pedal bone biopsy prior to any definitive surgical management.

This is the author manuscript accepted for publication and has undergone full peer review but has not been through the copyediting, typesetting, pagination and proofreading process, which may lead to differences between this version and the Version of Record. Please cite this article as doi: 10.1111/dme.13026

This article is protected by copyright. All rights reserved 


\section{Abstract}

\section{Introduction}

Diabetic foot infections are an important cause of hospitalization, health expenditure and mortality. Bone biopsy is the gold standard for diagnosing diabetic foot osteomyelitis [1] but it is not routinely performed in most centres. Instead, a combination of history, examination, biochemical and radiological findings are used to make the diagnosis. Here, we report a case mimicking diabetic foot osteomyelitis, where the histology was crucial in acquiring the correct diagnosis.

\section{Case report}

An 80-year-old man with a recent diagnosis of Type 2 diabetes mellitus presented to our hospital with a 3-month history of right foot pain, swelling and decreased mobility. There was no history of foot ulcers, trauma or previous surgery. He had completed a course of amoxicillin/clavulanic acid without any symptomatic improvement and currently had no systemic infective symptoms. His medications included sitagliptin $50 \mathrm{mg}$ daily and metformin $1 \mathrm{~g}$ daily with an $\mathrm{HbA}_{\mathrm{lc}}$ of $53 \mathrm{mmol} / \mathrm{mol}(7.0 \%)$ on admission. His diabetic complication status was significant for peripheral neuropathy affecting both feet. He had no other microvascular or macrovascular complications and no other significant past medical history.

Examination revealed an area of cellulitis overlying the lateral aspect of the right foot and calcaneus. There were no visible ulcers or wounds. He was insensate on monofilament testing with preserved foot architecture and palpable pedal pulses. $\mathrm{He}$ remained afebrile and haemodynamically stable throughout the admission.

Significant laboratory findings included raised inflammatory markers: C-reactive protein $70 \mathrm{mg} / \mathrm{l}$, white cell count $20.8 \times 10^{9} / 1$ with a predominant neutrophilia $17.7 \times 10^{9} / 1$ and normal alkaline phosphatase 80 IU/1. An erythrocyte sedimentation rate was not available on admission.

$\mathrm{X}$-Rays demonstrated isolated bony destruction of his calcaneus without involvement of other pedal bones. Computed tomography (CT) showed gross bony lysis of the calcaneum with a displaced fracture through the lateral aspect, generalized osteopenia and extensive soft tissue swelling (Fig. 1). These radiological features were reported 
to be consistent with advanced osteomyelitis and associated pathological fracture with no features of Charcot neuro-arthropathy.

The patient was commenced on intravenous pipercillin/tazobactam due to the presence of cellulitis and presumed diabetic foot osteomyelitis, and the clinical and biochemical features of inflammation improved. Because of the atypical presentation, a CT-guided biopsy and magnetic resonance imaging were organized to further evaluate the presumed diagnosis of diabetic foot osteomyelitis. However, prior to the diagnostic procedure, the patient elected to travel overseas for ongoing management due to financial constraints.

A positron emission tomography combined CT study was performed at an overseas centre and demonstrated hypermetabolic activity in the cutaneous and subcutaneous soft tissue of the right foot, together with multiple lymph nodes, skeletal system and pleura. An excisional biopsy of the right calcaneal lesion demonstrated high-grade malignant lymphoid cells accompanied by foci of necrosis. Immunostains were positive for $\mathrm{CD} 20$, bcl6 and bcl2, consistent with primary diffuse large B-cell lymphoma (DLBCL) of the bone. As a direct result of the biopsy, surgical management of the calcaneal abnormality was avoided and the patient was immediately referred to haematologists for management of the DLBCL.

Primary bone lymphoma is a rare neoplasm accounting for $<7 \%$ of all malignant bone tumours and $<1 \%$ of all lymphomas. The most common histological type of primary bone lymphoma is DLBCL and it usually affects the extremities with predilection for the femur [2]. Diagnosis is frequently delayed due to lack of pathognomonic radiographic changes and usually demonstrates an aggressive pattern of lytic bone destruction that can mimic other common pathologies [3].

\section{Discussion}

This case illustrates a rare case of primary DLBCL of the bone mimicking diabetic foot osteomyelitis and highlights the importance of diagnostic bone biopsy. The absence of an associated foot ulcer in presumed diabetic foot osteomyelitis should raise suspicion of potential rare mimics of diabetic foot osteomyelitis and bone biopsy should be considered to further evaluate the underlying aetiology prior to any definitive surgical management. In this case, excisional bone biopsy confirmed the malignant diagnosis, however, for atypical presentations of diabetic foot 
osteomyelitis, a percutaneous pedal bone biopsy should suffice. Given the increasing evidence for the medical management of diabetic foot osteomyelitis, bone biopsy is likely to be utilized more, not only to confirm the diagnosis, but also for tailoring appropriate antibiotic therapy $[4,5]$.

\section{Funding sources}

\section{Competing interests}

None declared.

\section{Acknowledgements}

\section{Author contributions}

SK, MK and PW wrote the article. PW is the guarantor of this work.

\section{Referenct}

1 Butalia S, Palda V, Sargeant R, Detsky A, Mourad O. Does this patient with diabetes have osteomyelitis of the lower extremity? JAMA 2008; 299: 806813.

2 Fletcher CD. The evolving classification of soft tissue tumours: an update based on the new WHO classification. Histopathology 2006; 48: 3-12.

3 Mulligan ME, McRae GA, Murphey MD. Imaging features of primary lymphoma of bone. Am J Roentgenol 1999; 173: 1691-1697.

4 Tone A, Nguyen S, Devemy F, Topolinski H, Valette M, Cazaubiel M et al. Six-week versus twelve-week antibiotic therapy for nonsurgically treated diabetic foot osteomyelitis: a multicenter open-label controlled randomized study. Diabetes Care 2015; 38: 302-307.

5 Lázaro-Mart́nez JL, Aragón-Sánchez J, Garćia-Morales E. Antibiotics versus conservative surgery for treating diabetic foot osteomyelitis: a randomized comparative trial. Diabetes Care 2014; 37: 789-795.

FIGURE 1 Reconstructed CT of the right foot demonstrating destruction of the calcaneus. 


\section{University Library}

\section{- M M I N E R VA A gateway to Melbourne's research publications}

Minerva Access is the Institutional Repository of The University of Melbourne

Author/s:

Kumar, S;Kyi, M;Wraight, PR

Title:

Rare mimic of pedal osteomyelitis in a patient with diabetes

Date:

2016-11-01

Citation:

Kumar, S., Kyi, M. \& Wraight, P. R. (2016). Rare mimic of pedal osteomyelitis in a patient with diabetes. DIABETIC MEDICINE, 33 (11), pp.E30-E31. https://doi.org/10.1111/dme.13026.

Persistent Link:

http://hdl.handle.net/11343/291852 